\title{
A quantitative evaluation based on an analytic hierarchy process for the deterioration degree of the Guangyuan Thousand-Buddha grotto from the Tang Dynasty in Sichuan, China
}

Xue Yao ${ }^{1 *}$ (ID and Fan Zhao ${ }^{2}$

\begin{abstract}
The Guangyuan Thousand-Buddha grotto is of great value in researching the spread of Buddhism in China. To explore a scientific deterioration degree evaluation method, the authors selected 11 grottos from the middle Tang Dynasty in the Guangyuan Thousand-Buddha grotto as survey objects; a traditional deterioration investigation was undertaken, and an analytic hierarchy process (AHP method) was applied to build a system to calculate the weight of 15 deterioration criteria and evaluate the deterioration degree of the grotto. The results showed that 15 deteriorations can be classified into two categories: stability deterioration and weathering deterioration. Each deterioration has its own weight on affecting the preservation condition of the grotto. In contrast to realistic conditions, the calculation results can quantitatively reflect the preservation condition of the grotto. The results offer a quantitative basis for determining the priority of grotto conservation and verifying the feasibility of the AHP method in helping conservators identify major deteriorations or judge conservation orders. This research proposes a quantitative evaluation method for the deterioration degree of the grotto, which can lay the foundation for further conservation of the grotto.
\end{abstract}

Keywords: Grotto, Quantitative evaluation, Analytic hierarchy process, Deterioration degree

\footnotetext{
*Correspondence: yaozhibushixue0726@126.com

${ }^{1}$ Department of Tourism and History Cultural, Southwest Minzu

University, Chengdu 610041, Sichuan, People's Republic of China

Full list of author information is available at the end of the article
} original author(s) and the source, provide a link to the Creative Commons licence, and indicate if changes were made. The images or other third party material in this article are included in the article's Creative Commons licence, unless indicated otherwise in a credit line to the material. If material is not included in the article's Creative Commons licence and your intended use is not permitted by statutory regulation or exceeds the permitted use, you will need to obtain permission directly from the copyright holder. To view a copy of this licence, visit http://creativecommons.org/licenses/by/4.0/. The Creative Commons Public Domain Dedication waiver (http://creativecommons.org/publicdomain/zero/1.0/) applies to the data made available in this article, unless otherwise stated in a credit line to the data. 


\section{Graphical Abstract}

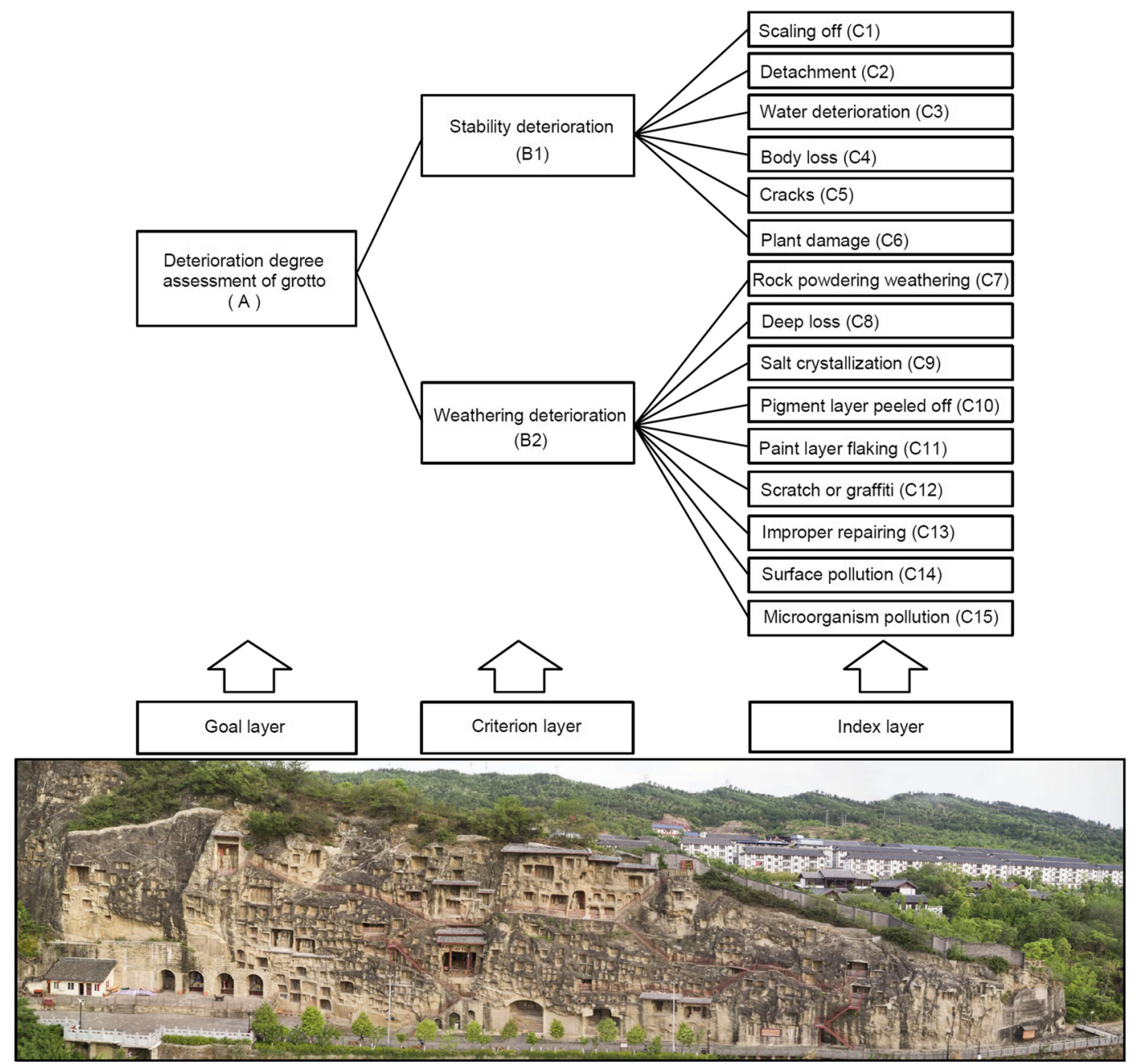

\section{Introduction}

Grottos are valuable heritage sites in China with high history, art and science values that began in the Han Dynasty and thrived from the North Wei Dynasty to the Tang Dynasty. They can be classified as Xinjiang grottos, north grottos, south grottos and Tibetan grottos according to regional and archaeological features [1]. The southern grottos refer to grottos distributed on the southern side of the Huaihe River of China, which arose in the eighth century and were usually excavated in sandstone formations [2]. Sandstone is easy to carve because of its relative softness, so the grottos and sculptures were often excavated at the sandstone mass directly, which has led to weathering, water deterioration and stability problems. According to statistics, the southern grottos account for 42.9\% of Chinese grottos, and the grottos in Sichuan and Chongqing account for more than $80 \%$ of the southern grottos [2]. A large number of grottos with high values are distributed in Sichuan Province, Southwest China. They are outstanding representatives of grottos from later times in Chinese history, which is meaningful when reconstructing the local history of Southwest China [3]. After experiencing hundreds of years of natural erosion and human destruction, most of these grottos have developed serious deteriorations that threaten their long-term existence and preservation. Existing research reveals that most grottos in Sichuan suffer from dangerous rock mass deterioration, sandstone degradation, water deterioration and biological deterioration due to the wet and rainy climate, soft sandstone properties and dense seismic zones $[2,4]$.

The preservation condition of grottos is affected by the combined functions of various factors, such as sandstone properties, grotto deterioration and environmental 
factors, including the geological environment, meteorological environment, biological environment and human environment [5]. Among these factors, deterioration obviously influences the preservation condition. Thus, grotto deterioration is a combined function of various factors, and the result is the joint contribution of multiple deteriorations. Grotto deterioration is usually represented by the type and quantity of deteriorations, which have been identified by field investigations [6, 7]. Weathering is the most common deterioration in the Gungyuan Thousand-Buddha grotto, which includes physical weathering and chemical weathering. Existing studies have revealed that temperature fluctuation and water deterioration are the main causes $[8,9]$. In most research, the degree of grotto deterioration has been characterized by qualitative descriptions such as "good", "moderate", "poor", and "very poor". The reality is that there is no common quantitative standard for the deterioration degree. This representative method depends on the subjective sense of investigators to a certain extent, although most of the investigators are professionals. Since the contribution of each deterioration is different, the qualitative representation cannot reflect the deterioration degree and the priority of different deteriorations [7], which leads to a lack of guidance for the conservation of grottos. Therefore, it is essential to research the weight of each deterioration and represent the deterioration degree in a quantitative method.

The analytic hierarchy process (AHP method) is an analysis method that combines qualitative and quantitative analysis and has been widely used in heritage assessment in recent years. Several applications of the AHP method for evaluating the risk or the value of heritage sites have been presented in national and international specialist literature. In the conservation of historic buildings, the AHP method was used for the comparison of various intervention alternatives on the basis of certain evaluation criteria aimed at obtaining a preference index [10]. Researchers from Lanzhou University analysed the stability of dense caves in southern areas of the Mogao grotto and evaluated the risk degree of dangerous rock bodies by using the AHP method and fuzzy AHP method. Thirteen indices were selected, and the overall hazard of the cliff was evaluated [11]. A hierarchical structure was established for researching the evaluation system for the development of scaling off of earthen sites in Northwest China, and the degree of scaling off development was calculated by using Fuzzy-AHP [12]. In conserving and reusing the industrial heritage, the AHP method and a fuzzy set were used to translate expert comments and build a value evaluation system. The result showed that the integration of AHP, fuzzy sets and D-S theory established a mathematical model providing a new approach for heritage conservation [13]. Researchers from Romania present the applicability of the AHP method, frequency ratio and statistical index in landslides in susceptibility mapping for heritage in dangerous areas, and the results revealed that although three calculation methods suggest different most important triggering factors, all three calculation models have shown good success [14]. In other research areas, the AHP method was used for risk assessment [15]. The AHP method combined with GIS was used to assess the hazard of floods near the world heritage in Thailand [16], while the same method was applied to evaluate the forest fire risk in Iran [17]. A risk assessment of water inrush to coal seams was conducted by TFN-AHP and TOPSIS techniques [18]. From the above content, we conclude that the AHP is a simple and efficient method to calculate the weight of the index and evaluate the goal layer. The existing related research in heritage conservation has focused on the risk assessment of one deterioration, such as the stability deterioration assessment in the Mogao grotto [11], an earthquake risk assessment system for grottos [19], or a rainstorm risk assessment for sites [20]. Generally, research on quantitative assessments of the integrated deterioration degree of grottos is inadequate. In this research, the AHP method was selected because it can reflect the subjective intention of the decision-maker, provide a hierarchical structure, facilitate decomposition and pairwise comparisons, reduce inconsistencies and generate priority vectors $[12$, 21]. The AHP method was used to establish a system for evaluating the deterioration degree of the grotto because of its combination of subjectivity and objectivity in this research. In this research, the authors selected 11 grottos from the Tang dynasty in the Guangyuan Thousand-Buddha grotto as the study objects. The AHP method is used to calculate the weight of each deterioration and characterize the deterioration degree of the grotto [22]. This research proposes a quick and simple calculation method for the deterioration weight and deterioration degree of the grotto and is an important component of the risk assessment of the grotto, which is beneficial for judging the urgency of the preservation condition of the grotto in a quick and effective way and offers a basis for conservation and consolidation.

\section{Study object}

The Guangyuan Thousand-Buddha grotto is located in Guangyuan, Sichuan Province (Fig. 1), which was excavated from the North Wei to Qing Dynasties [23]. The grotto was distributed on the face of a cliff alongside the east bank of the Jialing River. The Jinniu Road passes under the cliff, which was an important path through which Buddhism spread from central China to the Shu area [3]. In a digital investigation, 949 grottos and more 


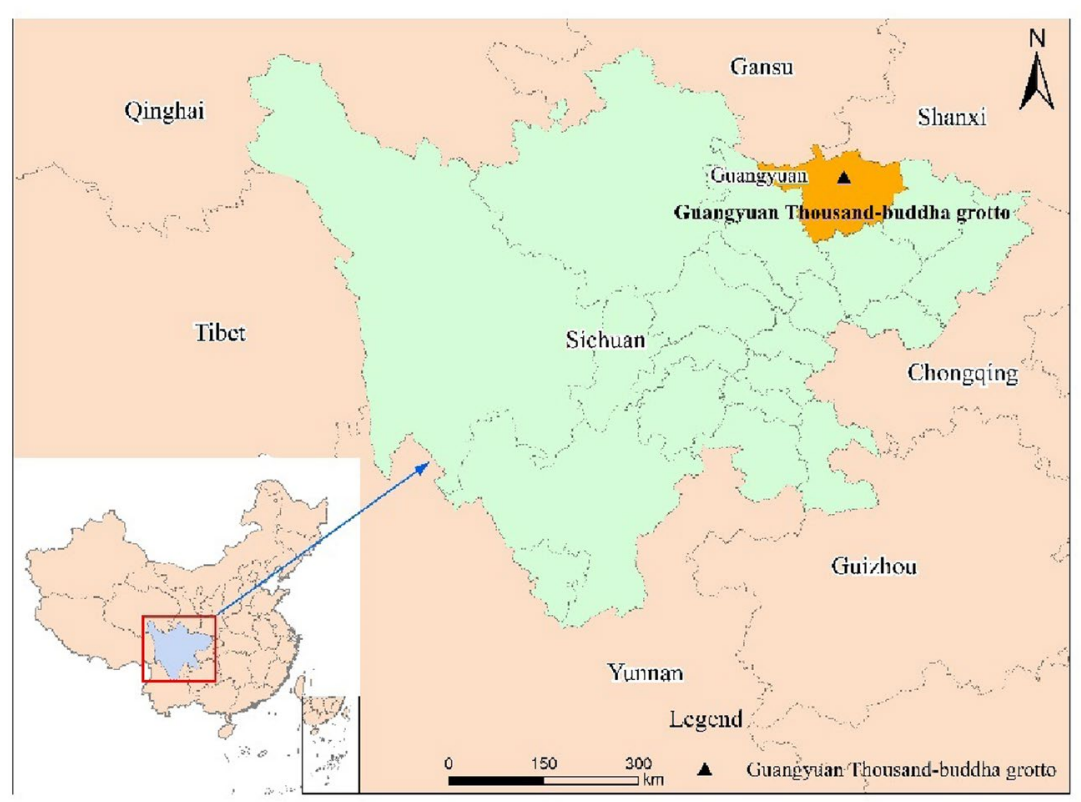

Fig. 1 The study area in this research (drawing by authors)

than 7000 stone sculptures were confirmed, most of which were created during the Tang Dynasty, presenting a high level of history, art and science value in the southern part of China. Owing to its high value and serious preservation, the Guangyuan Thousand-Buddha grotto was honoured as the first state-level key cultural relic preservation organization in 1961, and urgent repair treatments were needed [23]. However, several important questions must be answered before starting the work: Which deterioration is the most common and which is the most serious? Which deteriorations may lead to stability problems and which may result in weathering deterioration? Which grottos should be conserved first? Therefore, it is necessary to conduct a systematic and quantized deterioration investigation on the grotto, not only to answer these questions but also to offer a decision basis for conservation.

In this research, we selected 11 grottos excavated from the middle Tang Dynasty as research objects (Fig. 2) because of their outstanding value and representative art styles. They are NO.86, NO.211, NO.213, NO.214, NO.400, NO.512, NO.513, NO.535, NO.689, NO.805, and NO.806. Basic information about these grottos is listed in Table 1.

\section{Method}

\section{Field investigation}

Because of the similarity of the geotechnical cultural relics, in this research, a deterioration classification of earthen sites was used for reference [24]. Grotto deterioration is classified into two major categories based on the damage degree and scale [24]. One category is regional deterioration, which results from geological disasters such as landslides and debris flows. These deteriorations may lead to the disappearance or overall damage of grottos and often take place in the occurrence environment of grottos. Regional deterioration is beyond the scope of this research. The other is deterioration of the main body, namely, deterioration of the caves, sculptures or wall paintings. This kind of deterioration can be classified into two categories in more detail: one may lead to a stability problem, and the other may lead to a weathering problem [24]. In this research, the authors only surveyed the deteriorations on the main body of the grotto. There is no common standard for grotto deterioration classification. The deteriorations in this research were named by referring to the classification and legend on the deterioration of ancient stone objects (WW/T 0002-2007), issued by the State Administration of Cultural Heritage of the People's Republic of China [25]. Stability deteriorations involve scaling off, detachment, water deterioration, body loss, cracks and plant damage [2,25]. These deteriorations can affect the safety of the grotto directly, leading to body loss or disappearance. They have small quantities but develop quickly and destructively. The deteriorations that result in weathering problems can be classified as physical weathering, chemical weathering and biological weathering according to the formation mechanism [2]; in this research, they are 


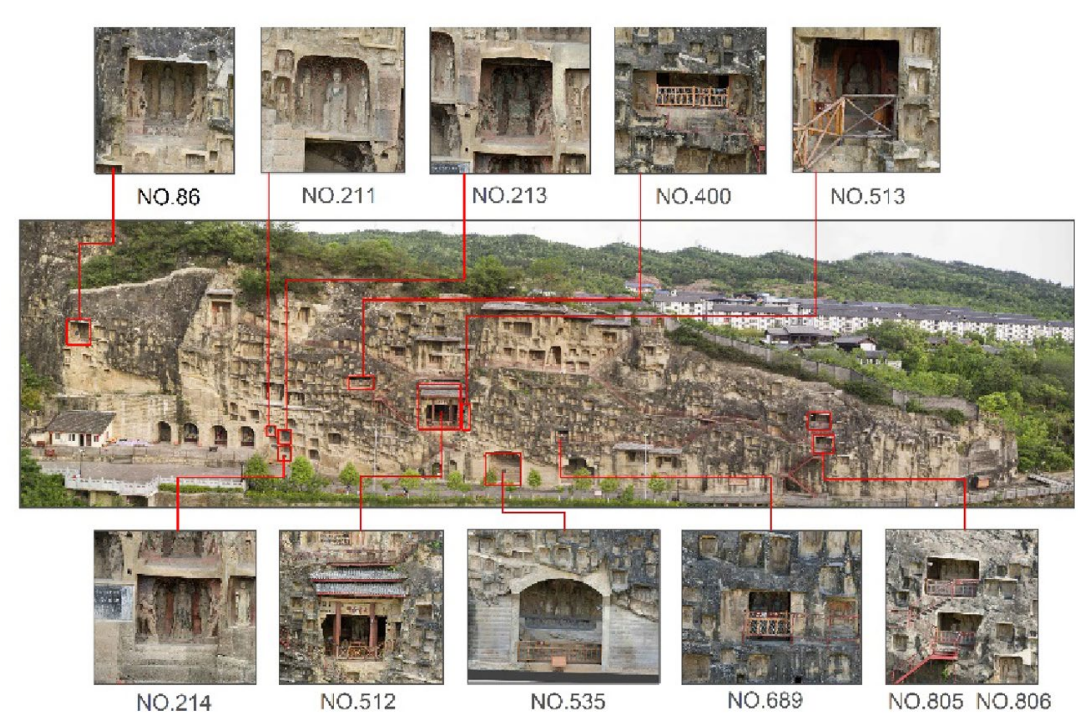

Fig. 2 The location of study objects in the Guangyuan Thousand-Buddha grotto (pictures from Guangyuan Thousand-Buddha Museum; drawing by authors)

Table 1 Basic information on grottos excavated from the middle Tang Dynasty

\begin{tabular}{|c|c|c|}
\hline NO & Name & Basic information \\
\hline 86 & Amitabha grotto & $\begin{array}{l}\text { This grotto was excavated from the middle Tang Dynasty, with a height of } 3.6 \mathrm{~m} \text { and depth of } 1.4 \mathrm{~m} \text {. The } \\
\text { preserved condition is good }\end{array}$ \\
\hline 211 & Suting grotto & $\begin{array}{l}\text { This grotto was excavated in } 723 \text { AD by the Suting. It is a circle arch grotto with a height of } 1.8 \mathrm{~m} \text {, width } \\
\text { of } 1.64 \mathrm{~m} \text {, and depth of } 0.85 \mathrm{~m}\end{array}$ \\
\hline 213 & / & NO.213 was excavated from the middle Tang Dynasty, and the detail time is not clear \\
\hline 214 & Vairocana Buddha grotto & This grotto was excavated from the early stage of Tang Kaiyuan \\
\hline 400 & Central Stupa grotto & $\begin{array}{l}\text { This is an uncompleted grotto. The outer cave is a horizontal rectangle. In the centre, a square column } \\
\text { was planned to be excavated but unfinished }\end{array}$ \\
\hline 512 & Dayun old grotto & $\begin{array}{l}\text { This grotto and NO.513 were both excavated by Weikang, a government official, from } 715 \text { to } 722 \text { AD. This } \\
\text { cave is located in the centre of whole Thousand-Buddha grotto and is the largest grotto }\end{array}$ \\
\hline 513 & Weikang grotto & This grotto and NO.512 were both excavated by Weikang, a government official, from 715 to 722 AD \\
\hline 535 & Lotus grotto & $\begin{array}{l}\text { This grotto was excavated from the Wuzhou period ( } 690-697 \text { AD) and is below the Thousand-Buddha } \\
\text { grotto (NO.689). At the inner top of the grotto there is a lotus, so it was named the "Lotus cave" }\end{array}$ \\
\hline 689 & Thousand-Buddha grotto & $\begin{array}{l}\text { This grotto was excavated from the middle Tang dynasty and the detail time is unclear. Since the sur- } \\
\text { rounding wall was sculpted with thousands of small buddhas, it was named the "Thousand-Buddha cave" }\end{array}$ \\
\hline 805 & Benefactor's grotto & $\begin{array}{l}\text { This grotto is NO.806, and there were } 6 \text { couples of benefactors sculpted in the grotto, so it was called the } \\
\text { "Benefactor's grotto" }\end{array}$ \\
\hline 806 & Shakyamuni and Prabhutaratna grotto & This grotto is located in the south end of the cliff and is named for its elegant sculpture \\
\hline
\end{tabular}

collectively called weathering deteriorations. There are nine weathering deteriorations based on the form, namely, rock powdering weathering, deep loss, salt crystallization, pigment layer peeling off, paint layer craquelure, scratch or graffiti, improper repair, surface pollution and microorganism pollution. They exist on the grotto for a long time and do not affect the safety of the grotto in the short term but will result in main body loss slowly in the long run. They are distributed widely with slow development and are weakly destructive. Obviously, the two kinds of deteriorations make different contributions to the grotto preservation condition. From this investigation, almost all these typical deteriorations can be found at the survey objects (Table 2). The deterioration data were investigated and collected in Tables 3 and 4. All data are from the Guangyuan Thousand-Buddha Museum. 
Table 2 Typical deteriorations in Guangyuan Thousand-Buddha grotto

\begin{tabular}{lll}
\hline Category & Deterioration & Description \\
\hline Stability deterioration & Scaling off & $\begin{array}{l}\text { Surface of the stone is peeled off as a slice or crust due to salt } \\
\text { dissolution and crystallization, temperature fluctuation, freezing } \\
\text { or weathering }\end{array}$
\end{tabular}

Detachment

Water deterioration

Body loss

Cracks

Plant damage
Surface of the stone is out of the grotto body and forms a cavity but is not peeled off

Water leakage, water incrustation inside the grotto due to rainfall, surface runoff and capillary water

The grotto or sculpture show a certain volume loss from its initial state

Includes three types: one is weathering fracture, often occurring on the surface; second is stress fracture, often extending to the inner stone, and may cause body loss or complete breakage; last is structural fracture, often closing, smoothing and appearing as a group

Plants grow in the cracks of grotto; the root may lead to more cracks

\section{Figure}
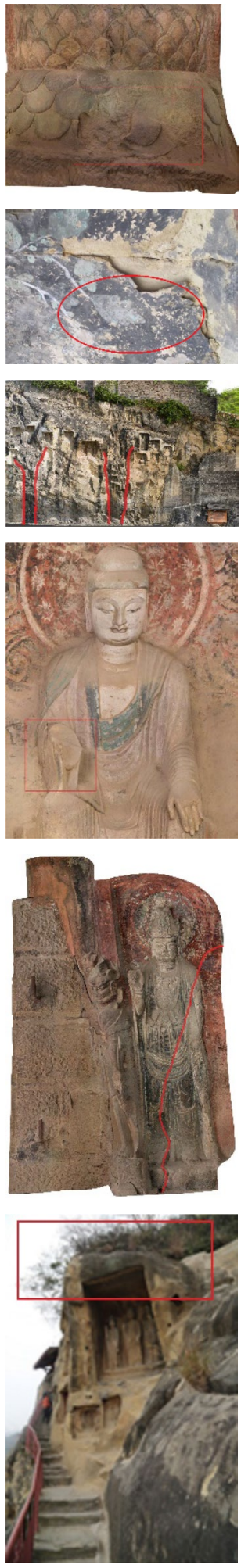
Table 2 (continued)

\begin{tabular}{|c|c|c|c|}
\hline Category & Deterioration & Description & Figure \\
\hline \multirow[t]{7}{*}{ Weathering deterioration } & Rock powdering weathering & $\begin{array}{l}\text { Surface of the stone is softened and peeled off because of tem- } \\
\text { perature and humidity fluctuation, freeze-thaw cycles, water } \\
\text { and salt activity }\end{array}$ & \\
\hline & Deep loss & $\begin{array}{l}\text { The plaster layer of paint in the grotto is peeled off from the } \\
\text { stone }\end{array}$ & \\
\hline & Salt crystallization & $\begin{array}{l}\text { Soluble salt dissolved and crystallized because of temperature } \\
\text { and humidity changes }\end{array}$ & \\
\hline & Pigment layer peeled off & $\begin{array}{l}\text { Paint layer of grotto flaked and broke away from the grotto or } \\
\text { sculpture }\end{array}$ & \\
\hline & Paint layer craquelure & $\begin{array}{l}\text { Paint layer of grotto cracked but not peeled off from the grotto } \\
\text { or sculpture }\end{array}$ & \\
\hline & Scratch or graffiti & Scratch or graffiti by human activity & \\
\hline & Improper repairing & $\begin{array}{l}\text { The grotto was repaired by improper materials or methods in } \\
\text { the past }\end{array}$ & \\
\hline
\end{tabular}


Table 2 (continued)

\begin{tabular}{|c|c|c|c|}
\hline Category & Deterioration & Description & Figure \\
\hline & Surface pollution & $\begin{array}{l}\text { Sootiness on the grotto or sculpture by smoke from the past. } \\
\text { Dust and weathering products cover the surface of the grotto }\end{array}$ & \\
\hline & Microorganism pollution & Microorganism grows on the grotto & \\
\hline
\end{tabular}

Table 3 Stability deterioration data

\begin{tabular}{|c|c|c|c|c|c|c|c|}
\hline \multirow[t]{2}{*}{ No } & \multirow[t]{2}{*}{ Name } & \multicolumn{6}{|c|}{ Stability deterioration } \\
\hline & & Scaling off $\left(\mathrm{m}^{2}\right)$ & $\begin{array}{l}\text { Detachment } \\
\left(\mathrm{m}^{2}\right)\end{array}$ & $\begin{array}{l}\text { Water } \\
\text { deterioration } \\
\left(\mathrm{m}^{2}\right)\end{array}$ & Body loss $\left(\mathrm{m}^{2}\right)$ & Cracks (m) & $\begin{array}{l}\text { Plant } \\
\text { damage } \\
\left(\mathrm{m}^{2}\right)\end{array}$ \\
\hline 86 & Amitabha grotto & 3.05 & 0.32 & 0.46 & 0.06 & 10.04 & 0.00 \\
\hline 211 & Suting grotto & 0.02 & 0.00 & 0.00 & 0.01 & 0.82 & 0.00 \\
\hline 213 & / & 0.47 & 0.07 & 0.00 & 0.03 & 5.36 & 0.00 \\
\hline 214 & Vairocana Buddha cave & 0.00 & 0.64 & 0.00 & 0.43 & 5.83 & 0.43 \\
\hline 400 & Central Stupa grotto & 0.13 & 0.33 & 3.06 & 0.01 & 15.20 & 0.00 \\
\hline 512 & Dayun old cave & 10.28 & 0.19 & 0.64 & 0.95 & 27.12 & 0.01 \\
\hline 513 & Weikang grotto & 0.83 & 0.00 & 0.00 & 0.57 & 4.52 & 0.00 \\
\hline 535 & Lotus cave & 1.98 & 1.04 & 0.00 & 0.14 & 21.89 & 0.00 \\
\hline 689 & Thousand-Buddha cave & 5.06 & 0.00 & 0.00 & 0.14 & 5.76 & 0.00 \\
\hline 805 & Benefactor's grotto & 0.52 & 0.20 & 0.00 & 0.03 & 9.83 & 0.00 \\
\hline 806 & $\begin{array}{l}\text { Shakyamuni and Prabhuta- } \\
\text { ratna grotto }\end{array}$ & 2.29 & 0.09 & 0.00 & 0.04 & 4.00 & 0.00 \\
\hline
\end{tabular}

\section{AHP method}

The analytic hierarchy process is a multi-objective decision analysis method that combines qualitative and quantitative analysis, applies to a large complex system with a complex target structure, or lacks certain data $[21,26]$. The basic principle is to decompose the decision goal according to different standards, calculate the weight of each element to a specific element in the above layer by calculating the matrix and eigenvector, and finally conclude the weight of every element in this system [21]. The final goal of the AHP method is to determine the relative weight of every element in the system. The specific procedure of this method is shown as follows (Fig. 3).
The AHP method procedures are as follows $[12,17,18$, 21, 27]:

Step 1: Clarify the decision goal. In this research, the decision goal was to evaluate the degree of grotto deterioration.

Step 2: Build hierarchical structure. The hierarchical structure of the deterioration degree was established according to the deterioration classification of the grotto.

Step 3: Construct judgement matrix. In this step, the weights of the indices in the hierarchical structure are calculated.

First, compare the elements of a particular layer pairwise in accordance with expert opinion; then, matrix A can be given as follows (Eq. 1): 
Table 4 Weathering deterioration data

\begin{tabular}{|c|c|c|c|c|c|c|c|c|}
\hline \multirow[t]{2}{*}{ No } & \multirow[t]{2}{*}{ Name } & \multicolumn{7}{|c|}{ Weathering deterioration } \\
\hline & & \multicolumn{2}{|c|}{$\begin{array}{l}\text { Rock powdering } \\
\text { weathering }\left(\mathrm{m}^{2}\right)\end{array}$} & \multicolumn{2}{|c|}{ Deep loss $\left(m^{2}\right)$} & $\begin{array}{l}\text { Salt crystallization } \\
\left(\mathrm{m}^{2}\right)\end{array}$ & $\begin{array}{l}\text { Pigment layer } \\
\text { peeled off }\left(\mathrm{m}^{2}\right)\end{array}$ & $\begin{array}{l}\text { Paint layer } \\
\text { craquelure } \\
\left(\mathrm{m}^{2}\right)\end{array}$ \\
\hline 86 & Amitabha grotto & 7.67 & & 0.01 & & 0.60 & 2.76 & 1.59 \\
\hline 211 & Suting grotto & 0.15 & & 0.00 & & 0.09 & 0.13 & 0.00 \\
\hline 213 & / & 2.95 & & 0.03 & & 0.13 & 1.14 & 0.31 \\
\hline 214 & Vairocana Buddha cave & 0.10 & & 0.07 & & 0.00 & 0.36 & 0.48 \\
\hline 400 & Central Stupa grotto & 15.92 & & 0.58 & & 5.91 & 0.26 & 0.06 \\
\hline 512 & Dayun old cave & 19.16 & & 0.06 & & 4.98 & 1.92 & 0.01 \\
\hline 513 & Weikang grotto & 4.49 & & 0.02 & & 0.00 & 2.24 & 0.00 \\
\hline 535 & Lotus cave & 12.47 & & 0.01 & & 1.71 & 5.25 & 0.09 \\
\hline 689 & Thousand-Buddha cave & 7.62 & & 0.01 & & 0.86 & 4.27 & 0.00 \\
\hline 805 & Benefactor's grotto & 18.67 & & 0.00 & & 0.72 & 0.12 & 3.27 \\
\hline 806 & $\begin{array}{l}\text { Shakyamuni and Prabhutar- } \\
\text { atna grotto }\end{array}$ & 17.69 & & 0.00 & & 0.14 & 5.27 & 0.78 \\
\hline \multirow[t]{2}{*}{ No } & \multirow[t]{2}{*}{ Name } & & \multicolumn{6}{|c|}{ Weathering deterioration } \\
\hline & & & \multicolumn{2}{|c|}{ Scratch or graffiti (m) } & \multicolumn{2}{|c|}{$\begin{array}{l}\text { Improper repairing } \\
\left(\mathrm{m}^{2}\right)\end{array}$} & Surface pollution $\left(\mathrm{m}^{2}\right)$ & $\begin{array}{l}\text { Microorganism } \\
\text { pollution }\left(\mathrm{m}^{2}\right)\end{array}$ \\
\hline 86 & \multicolumn{2}{|l|}{ Amitabha grotto } & \multicolumn{2}{|l|}{0.00} & \multicolumn{2}{|l|}{0.10} & 5.79 & 0.01 \\
\hline 211 & \multicolumn{2}{|l|}{ Suting grotto } & \multicolumn{2}{|l|}{0.00} & \multicolumn{2}{|l|}{0.00} & 1.48 & 0.00 \\
\hline 213 & \multicolumn{2}{|l|}{ / } & \multicolumn{2}{|l|}{0.00} & \multicolumn{2}{|l|}{0.63} & 1.46 & 0.00 \\
\hline 214 & \multicolumn{2}{|l|}{ Vairocana Buddha cave } & \multicolumn{2}{|l|}{5.90} & \multicolumn{2}{|l|}{0.12} & 0.00 & 0.01 \\
\hline 400 & \multicolumn{2}{|l|}{ Central Stupa grotto } & 36.94 & & \multicolumn{2}{|l|}{0.07} & 2.61 & 1.35 \\
\hline 512 & Dayun old cave & & 15.15 & & 3.00 & & .86 & 0.37 \\
\hline 513 & Weikang grotto & & 21.07 & & 0.05 & & .27 & 0.05 \\
\hline 535 & Lotus cave & & 12.83 & & 0.84 & & 3.60 & 5.70 \\
\hline 689 & Thousand-Buddha cav & & 88.53 & & 0.09 & & 3.18 & 0.01 \\
\hline 805 & Benefactor's grotto & & 58.17 & & 0.01 & & 3.57 & 1.86 \\
\hline 806 & $\begin{array}{l}\text { Shakyamuni and Prabh } \\
\text { grotto }\end{array}$ & utaratna & 70.65 & & 0.05 & & 3.01 & 1.70 \\
\hline
\end{tabular}

$$
A=\left(a_{i j}\right)_{n \times n}
$$

$\mathrm{n}$ is the number of elements compared, and $a_{i j}$ is governed by the following rules: $a_{i j}>0 ; a_{i j}=1 / a_{i j}(\mathrm{i} \neq j)$, $a_{i j}=1(i=j=1,2 \ldots n)$.

$a_{i j}$ is the element of matrix $\mathrm{A}$, and the value of $a_{i j}$ is from the judgement of a pair of elements $A_{i}$ and $A_{j}$, which indicate the relative importance of two elements. The value of $a_{i j}$ is defined from a 9-point scale (Table 5). In this table, the value of relative importance is expressed as pairwise weights of $1,3,5,7$ and 9, which means that the relative importance between elements is equally, moderately, strongly, very strongly and extremely important. Values of 2, 4, 6, and 8 are intermediate values [26].

Second, calculate the weight of each index to a particular criterion in the above layer. The matrix A' can be calculated according to Eq. (2), and the eigenvector of each column in matrix A can be calculated according to Eq. (3). Finally, by normalizing the eigenvector of each column according to Eq. (4), the weight of each index can be calculated.

$$
\begin{aligned}
& A_{i j}^{\prime}=\frac{A_{i j}}{\sum A_{i j}} \\
& \overline{W \mathrm{i}}=\sum_{j=1}^{n} \overline{W i j} \\
& W \mathrm{i}=\frac{\overline{\mathrm{Wi}}}{\sum \mathrm{Wi}}
\end{aligned}
$$

Step 4: Check consistency. To avoid the inconsistency of the decision system, it is necessary to verify the consistency of the matrix. When the random consistency 

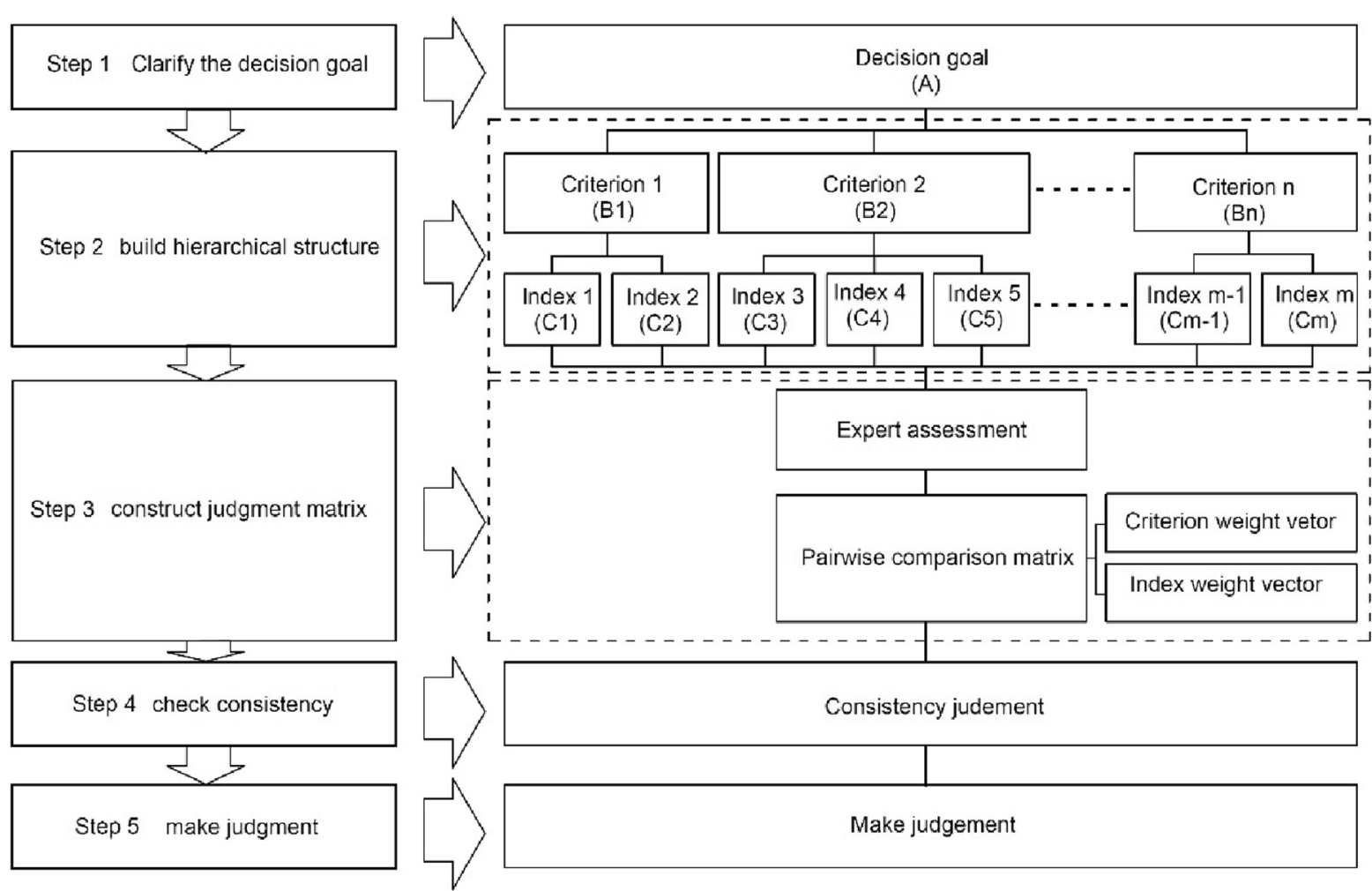

Fig. 3 AHP Method procedure (drawing by authors)

Table 5 Relative importance meaning of pairwise value

\begin{tabular}{ll}
\hline Value & Meaning \\
\hline 1 & The relative importance of $A_{i}$ and $A_{j}$ is equal \\
3 & $A_{i}$ is moderately more important than $A_{j}$ \\
5 & $A_{i}$ is strongly more important than $A_{j}$ \\
7 & $A_{i}$ is much more strongly important than $A_{j}$ \\
9 & $A_{i}$ is extremely more strongly important than $A_{j}$ \\
$2,4,6,8$ & The relative importance between $1,3,5,7,9$ in turns \\
\hline
\end{tabular}

index (C. R) is less than or equal to 0.1 , the matrix can be regarded as consistent. The $\mathrm{C}$. I can be calculated according to Eq. (5), and C. R can be calculated according to Eq. (6) [21].

$$
\text { C.I. }=\left(\lambda_{\max }-n\right) /(n-1)
$$

$$
\text { C.R. }=\text { C.I. } / \text { R.I }
$$

In Eq. (5), $\lambda_{\max }$ is the largest eigenvalue of matrix $A, n$ is the scale of the matrix, and $\mathrm{R}$. I is the average random consistency index, which is a constant according to the scale of the matrix (Table 6).

Step 5: Make judgement. By calculating the weight and normalizing the quantity of deterioration in each grotto, the deterioration degree of the grotto can be calculated.

\section{Result}

In this part, the authors established a hierarchical structure of the deterioration degree of the grotto, calculated the weight of each deterioration in the hierarchical structure and finally obtained the deterioration degree of each grotto.

Table 6 The random index (R. I) values

\begin{tabular}{llllllllll}
\hline Scale & $\mathbf{1}$ & $\mathbf{2}$ & $\mathbf{3}$ & $\mathbf{4}$ & $\mathbf{5}$ & $\mathbf{6}$ & $\mathbf{7}$ & $\mathbf{8}$ & $\mathbf{1 0}$ \\
\hline R.I & 0 & 0 & 0.58 & 0.9 & 1.12 & 1.24 & 1.32 & 1.41 & 1.45 \\
\hline
\end{tabular}




\section{Building hierarchical structure}

Selecting proper evaluation indices and building a reasonable hierarchical structure are important for evaluating the degree of grotto deterioration. In this research, evaluating the deterioration degree of a grotto in a quantitative way is the goal. From the final result, the deterioration degree is the joint effect of various deteriorations. The authors selected stability deteriorations and weathering deteriorations as the criterion layers of the hierarchical structure. These two kinds of deteriorations influence the degradation process in different models. According to the investigation, the stability deteriorations have less quantity, but develop fast and are more dangerous, while the weathering deteriorations distribute widely but develop at a low speed, existing in a long term. These two kinds of deterioration make different contributions to the deterioration degree. It is necessary to consider both the quantity and weight of each deterioration when defining the deterioration degree. Based on the results of the field investigation and reasonable deterioration identification, 15 common deteriorations that can be classified into the two categories above based on their destructive models are determined as the index layer. The hierarchical structure of the deterioration degree of the grotto is established as shown in Fig. 4.

\section{Stability deterioration}

In this research, the survey objects were excavated at the rock mass directly, and stability deterioration means that the mechanical equilibrium of the rock mass was broken by different factors, which will result in the buckling deformation of grottos. Once stability deterioration occurs, it means that the grottos have the risk of collapse.

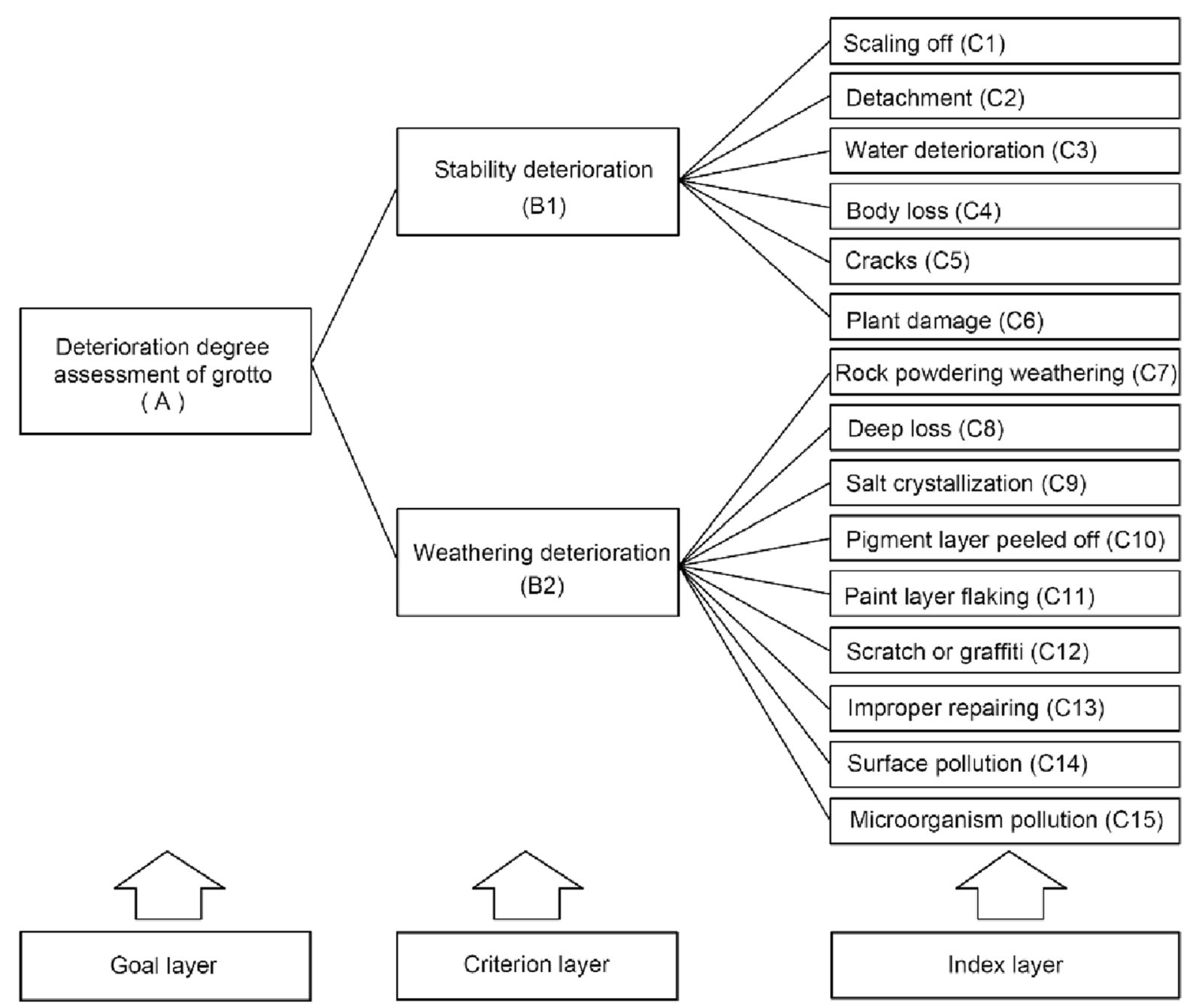

Fig. 4 The hierarchical structure of grotto's deterioration degree assessment (drawing by authors) 
The index under this criterion layer will cause the stability to deteriorate directly.

\section{Scaling off}

Scaling off is the surface of the stone peeling off from the main body of the grottos or sculptures as slices or crusts. This deterioration emphasizes the state of falling off from the stone. A large area of scaling off at the base of the grotto or the rock mass will lead to instability $[2,25]$.

\section{Detachment}

Detachment is the surface of the stone that separates from the main body and forms a cavity but does not fall off. This deterioration emphasizes the formation of a cavity, and it will develop into scaling off under the influence of various factors, ultimately falling off $[2,25]$.

\section{Water deterioration}

Water deterioration is the most common deterioration in southern grottos [2, 25]. Water includes rainfall, surface runoff and capillary water, and deterioration often works with large cracks. The intensity of rock will decrease under water deterioration, and instability and collapse occur.

\section{Body loss}

Body loss is a state in which the main body of the grotto, sculpture or wall painting has been lost for different reasons. Some of the body loss occurred at the free face or the base of the grotto, which led to buckling deformation of the grotto or sculpture.

\section{Cracks}

Large cracks will cut the rock as dangerous rock bodies, and as a function of water deterioration, it will lead to instability of the rock mass or grotto leakage $[2,25]$.

\section{Plant damage}

Plant damage in this research means the damage caused by large bushes or trees. The root systems of plants often grow along cracks, leading to water leakage into the grotto. Under the comprehensive function of cracks and water, the grottos easily become unstable.

\section{Weathering deterioration}

Physical weathering, chemical weathering and biological weathering are collectively called weathering deterioration in this research and include rock weathering and painting layer weathering. Weathering deterioration was the most common deterioration in the Guangyuan Thousand-Buddha grotto and was distributed in almost every grotto. This kind of deterioration often occurs at the surface of the rock with slow development and will not result in obvious destruction in a short time. There are 9 indices under this criterion. Rock powdering weathering, pigment layer peeling off, paint layer craquelure, scratch or graffiti and improper repair are physical weathering since they only change the physical state of rock or pigment. Deep loss, salt crystallization and surface pollution are chemical weathering because they all lead to chemical change. Microorganism pollution is the only biological weathering. All the destructive methods are introduced in Table 2.

\section{Constructing a judgement matrix}

In this research, the deterioration degree evaluation of the grotto is the goal, and stability deterioration and weathering deterioration are criterion layers. The index layer includes 15 deteriorations.

To ensure the reliability of the survey results, experts who are well acquainted with grottos in China were invited to provide the final comparison results for the structure pairwise comparison matrices. Considering the different opinions of different roles in grotto conservation, such as grotto managers, researchers and conservators, the experts participating in the questionary include researchers from colleges, conservators in archaeological institutions, and managers in relic management, all of whom have rich experience in grotto research and conservation. The detailed information of these experts is shown in Table 7. The pairwise comparison matrix and the calculation result are shown in Table 8 . The weight is calculated through Eqs. (2) (4).

The result in Table 8 is the weight of deterioration to the criterion layer, and the total sequencing weight and the weight ranking in the system are shown in Table 9.

Table 7 Detail information of experts

\begin{tabular}{lllllrr}
\hline NO & Age & Major & Education level & Occupation & Career year & Employer \\
\hline NO.1 & 34 & Grotto conservation & Master of Archaeology & Researcher & 9 & Research institute \\
NO.2 & 42 & Heritage management & Doctor of Archaeology & Manager of grotto & 14 & Management \\
NO.3 & 54 & Grotto archaeology & Doctor of Archaeology & Professor & 32 & College \\
\hline
\end{tabular}


Table 8 Pairwise comparison result of the criterion layer

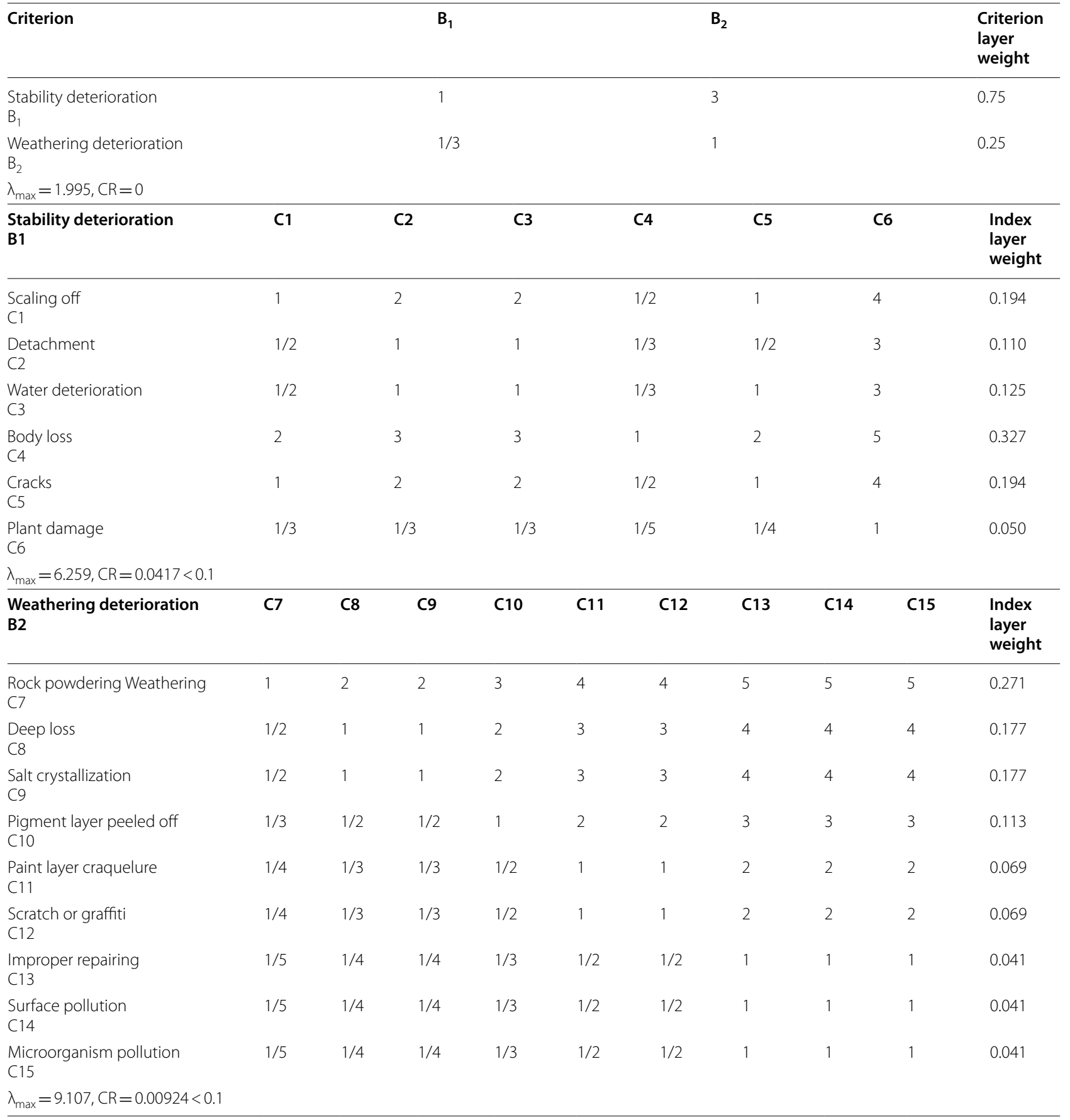

\section{Checking consistency}

To avoid the inconsistency of the pairwise index in the system, consistency checking is necessary. When only the C.I. and C.R. were both less than or equal to 0.1, the result above was confirmed. According to Eqs. (5) and (6), the consistency of matrix $B_{1}$ and matrix $B_{2}$ is checked (Table 10).

\section{Assessing the deterioration degree}

The calculation result shows the contribution of each deterioration to the deterioration degree. Here, the authors started to evaluate the deterioration degree. Owing to the various units of 15 deteriorations, there is no comparability between different deteriorations, and the data cannot be weighted. It is necessary to process 
Table 9 Comprehensive weight acquired by AHP

\begin{tabular}{|c|c|c|c|c|c|}
\hline Criterion layer & $\begin{array}{l}\text { Criterion layer } \\
\text { weight }\left(\mathrm{W}_{\mathrm{bi}}\right)\end{array}$ & Index layer & $\begin{array}{l}\text { Index layer weight } \\
\left(\mathrm{W}_{\mathrm{ci}}\right)\end{array}$ & $\begin{array}{l}\text { Total sequencing weight } \\
\left(\mathrm{Wn}=\mathrm{W}_{\mathrm{bi}} \times \mathrm{W}_{\mathrm{ci}}\right)\end{array}$ & $\begin{array}{l}\text { Weight } \\
\text { ranking in } \\
\text { system }\end{array}$ \\
\hline \multirow{6}{*}{$\begin{array}{l}\text { Stability deterioration } \\
\mathrm{B}_{1}\end{array}$} & \multirow[t]{6}{*}{0.75} & $C_{1}$ & 0.194 & 0.146 & 2 \\
\hline & & $C_{2}$ & 0.110 & 0.083 & 4 \\
\hline & & $C_{3}$ & 0.125 & 0.094 & 3 \\
\hline & & $\mathrm{C}_{4}$ & 0.327 & 0.246 & 1 \\
\hline & & $C_{5}$ & 0.194 & 0.146 & 2 \\
\hline & & $\mathrm{C}_{6}$ & 0.050 & 0.037 & 7 \\
\hline \multirow{9}{*}{$\begin{array}{l}\text { Weathering deterioration } \\
\mathrm{B}_{2}\end{array}$} & \multirow[t]{9}{*}{0.25} & $C_{7}$ & 0.271 & 0.068 & 5 \\
\hline & & $\mathrm{C}_{8}$ & 0.177 & 0.044 & 6 \\
\hline & & $C_{9}$ & 0.177 & 0.044 & 6 \\
\hline & & $C_{10}$ & 0.113 & 0.028 & 8 \\
\hline & & $C_{11}$ & 0.069 & 0.017 & 9 \\
\hline & & $C_{12}$ & 0.069 & 0.017 & 9 \\
\hline & & $C_{13}$ & 0.041 & 0.010 & 10 \\
\hline & & $C_{14}$ & 0.041 & 0.010 & 10 \\
\hline & & $C_{15}$ & 0.041 & 0.010 & 10 \\
\hline
\end{tabular}

Table 10 Consistency checking result

\begin{tabular}{llll}
\hline Matrix & C.I & C.R & Consistency \\
\hline Matrix $B_{1}$ & 0.0518 & 0.0417 & consistent \\
Matrix $B_{2}$ & 0.0134 & 0.00924 & consistent \\
\hline
\end{tabular}

the deterioration data in a dimensionless fashion to solve the incomparability between different deteriorations. In this research, the equalization method is adopted according to Eq. (7) [11].

$$
x_{i}^{\prime}=\frac{x_{i}-x_{\min }}{x_{\max }-x_{\min }}
$$

In Eq. (7), $x_{i}{ }^{\prime}$ is the dimensionless processing data, $x_{i}$ is the initial deterioration data from Tables 3 and 4, and $x_{\min }$ and $x_{\text {max }}$ are the minimum and maximum of every column in Tables 3 and 4, respectively. The processing data are in Tables 11 and 12.

The deterioration degree of the grotto is characterized by the quantity and weight of every deterioration. Therefore, the grotto deterioration degree can be calculated as Eq. (8) below [11].

Table 11 Dimensionless processing data of stability deterioration

\begin{tabular}{|c|c|c|c|c|c|c|}
\hline \multirow[t]{2}{*}{ No } & \multicolumn{6}{|c|}{ Stability deterioration } \\
\hline & Scaling off & Detachment & Water deterioration & Body loss & Cracks & Plant damage \\
\hline 86 & 0.297 & 0.308 & 0.150 & 0.053 & 0.351 & 0.000 \\
\hline 211 & 0.002 & 0.000 & 0.000 & 0.000 & 0.000 & 0.000 \\
\hline 213 & 0.046 & 0.067 & 0.000 & 0.021 & 0.173 & 0.000 \\
\hline 214 & 0.000 & 0.615 & 0.000 & 0.447 & 0.190 & 1.000 \\
\hline 400 & 0.013 & 0.317 & 1.000 & 0.000 & 0.547 & 0.000 \\
\hline 512 & 1.000 & 0.183 & 0.209 & 1.000 & 1.000 & 0.023 \\
\hline 513 & 0.081 & 0.000 & 0.000 & 0.596 & 0.141 & 0.000 \\
\hline 535 & 0.193 & 1.000 & 0.000 & 0.138 & 0.801 & 0.000 \\
\hline 689 & 0.492 & 0.000 & 0.000 & 0.138 & 0.188 & 0.000 \\
\hline 805 & 0.051 & 0.192 & 0.000 & 0.021 & 0.343 & 0.000 \\
\hline 806 & 0.223 & 0.087 & 0.000 & 0.032 & 0.121 & 0.000 \\
\hline
\end{tabular}


Table 12 Dimensionless processing data of weathering deterioration

\begin{tabular}{|c|c|c|c|c|c|c|c|c|}
\hline \multirow[t]{2}{*}{ No } & \multicolumn{8}{|c|}{ Weathering deterioration } \\
\hline & \multicolumn{2}{|c|}{$\begin{array}{l}\text { Rock powdering } \\
\text { weathering }\end{array}$} & \multicolumn{2}{|l|}{ Deep loss } & \multicolumn{2}{|l|}{ Salt crystallization } & Pigment layer peeled off & $\begin{array}{l}\text { Paint layer } \\
\text { craquelure }\end{array}$ \\
\hline 86 & 0.402 & & 0.017 & & 0.102 & & 0.513 & 0.486 \\
\hline 211 & 0.007 & & 0.000 & & 0.015 & & 0.002 & 0.000 \\
\hline 213 & 0.154 & & 0.052 & & 0.022 & & 0.198 & 0.095 \\
\hline 214 & 0.005 & & 0.121 & & 0.000 & & 0.047 & 0.147 \\
\hline 400 & 0.835 & & 1.000 & & 1.000 & & 0.027 & 0.018 \\
\hline 512 & 1.005 & & 0.103 & & 0.843 & & 0.350 & 0.003 \\
\hline 513 & 0.235 & & 0.034 & & 0.000 & & 0.412 & 0.000 \\
\hline 535 & 0.654 & & 0.017 & & 0.289 & & 0.996 & 0.028 \\
\hline 689 & 0.399 & & 0.017 & & 0.146 & & 0.806 & 0.000 \\
\hline 805 & 0.979 & & 0.000 & & 0.122 & & 0.000 & 1.000 \\
\hline 806 & 0.928 & & 0.000 & & 0.024 & & 1.000 & 0.239 \\
\hline \multirow[t]{2}{*}{ No } & \multicolumn{8}{|c|}{ Weathering deterioration } \\
\hline & \multicolumn{3}{|c|}{ Scratch or graffiti } & \multicolumn{2}{|c|}{ Improper repairing } & \multicolumn{2}{|c|}{ Surface pollution } & $\begin{array}{l}\text { Microorganism } \\
\text { pollution }\end{array}$ \\
\hline 86 & \multicolumn{3}{|c|}{0.000} & \multicolumn{2}{|l|}{0.033} & \multicolumn{2}{|l|}{0.533} & 0.002 \\
\hline 211 & \multicolumn{2}{|r|}{0.000} & \multicolumn{3}{|c|}{0.000} & 0.136 & & 0.000 \\
\hline 213 & \multicolumn{2}{|r|}{0.000} & \multicolumn{3}{|c|}{0.210} & 0.134 & & 0.000 \\
\hline 214 & \multicolumn{2}{|r|}{0.067} & \multicolumn{3}{|c|}{0.040} & 0.000 & & 0.002 \\
\hline 400 & \multicolumn{2}{|r|}{0.417} & \multicolumn{3}{|c|}{0.023} & 0.240 & & 0.237 \\
\hline 512 & \multicolumn{2}{|r|}{0.171} & \multicolumn{3}{|c|}{1.000} & 1.000 & & 0.065 \\
\hline 513 & & 0.238 & & 0.017 & & 0.117 & & 0.009 \\
\hline 535 & & 0.145 & & 0.280 & & 0.792 & & 1.000 \\
\hline 689 & & 1.000 & & 0.030 & & 0.293 & & 0.002 \\
\hline 805 & & 0.657 & & 0.003 & & 0.329 & & 0.326 \\
\hline 806 & & 0.798 & & 0.017 & & 0.277 & & 0.298 \\
\hline
\end{tabular}

$$
D=\sum_{i=1}^{n} W_{i} x_{i}^{\prime}
$$

$\mathrm{D}$ is the deterioration degree, and the deterioration degree of 11 survey objects is shown in Table 13 .

The result shows that the deterioration degree value of 11 grottos ranges between 0 and 0.8 ; the authors equally divided the value as 4 level based on expert opinions since there is no common principle about the classification of grotto deterioration degree. The grotto deterioration degree was classified as good $(0-0.2]$, moderate $(0.2 \sim 0.4]$, poor $(0.4 \sim 0.6]$, or very poor $(0.6 \sim 0.8]$, and the grotto deterioration degrees are shown in Table 14 .

The results reveal that four grotto (NO.211, NO.213, NO.805, NO.806) deterioration degree values ranged between 0 and 0.2 and that their preservation conditions were good. Six grotto deterioration degree values were between 0.2 and 0.4 , and their preservation conditions were moderate (NO.86, NO.214. NO.400, NO.513,

Table 13 Value of deterioration degree of 11 grottos

\begin{tabular}{lccrrrr}
\hline NO & $\mathbf{8 6}$ & $\mathbf{2 1 1}$ & $\mathbf{2 1 3}$ & $\mathbf{2 1 4}$ & $\mathbf{5 1 2}$ \\
\hline Value of deterioration degree & 0.208 & 0.003 & 0.067 & 0.237 & $\mathbf{6 8 9}$ & $\mathbf{8 0 5}$ \\
\hline NO & $\mathbf{5 1 3}$ & $\mathbf{5 3 5}$ & 0.360 & $\mathbf{8 0 6}$ \\
\hline Value of deterioration degree & 0.213 & 0.372 & 0.181 & 0.185
\end{tabular}


Table 14 Grotto deterioration degree levels

\begin{tabular}{|c|c|c|c|}
\hline Preserve condition & Deterioration degree value & Number of grottos & $\begin{array}{l}\text { Total grotto } \\
\text { number of the } \\
\text { level }\end{array}$ \\
\hline Good & $(0-0.2]$ & NO.211, NO.213, NO.805, N0.806 & 4 \\
\hline Moderate & $(0.2 \sim 0.4]$ & NO.86, NO.214. NO.400, NO.513, NO.535, N0.689 & 6 \\
\hline Poor & $(0.4 \sim 0.6]$ & / & 0 \\
\hline Very poor & $(0.6 \sim 0.8]$ & NO.512 & 1 \\
\hline
\end{tabular}

NO.535, NO.689). Only one grotto deterioration degree value was between 0.6 and 0.8 , which indicated that the preservation condition was very poor (NO.512).

\section{Discussion}

The weight of stability deterioration is 0.75 , which means that this kind of deterioration has a greater impact on the deterioration degree, while the weight of weathering deterioration is 0.25 . The weight of 15 deteriorations in descending order is body loss (C4), scaling off (C1), cracks (C5), water deteriorations (C3), detachment (C2), rock powdering weathering $(\mathrm{C} 7)$, deep loss $(\mathrm{C} 8)$, salt crystallization (C9), plant damage (C6), pigment layer peeled off (C10), paint layer craquelure (C11), scratch or graffiti (C12), improper repairing (C13), surface pollution (C14), and microorganism pollution $(\mathrm{C} 15)$. This reflects that the larger the weight of the deterioration is, the greater its impact on the deterioration degree. According to the weight (as shown in Table 9 Column 5), body loss, scaling off, cracks and water deterioration are the main deteriorations in the Guangyuan Thousand-Buddha grotto, and they have great impact on grottos deterioration degree since they may directly lead to stability problems. The formation of these four deteriorations is strongly associated with the soft properties of sandstone, rainy and wet climates and dense seismic zones. In the investigation, weathering deterioration was the most common deterioration, especially rock powdering weathering, and the paint layer peeled off, which can be found in almost every grotto. According to the deterioration data shown in Table 4, Column 3 and Column 6, the amount of rock powdering weathering and paint layer peeled off is much larger than other deteriorations. However, they have less weight on the grotto deterioration degree, as shown in Table 9. Because the destructive mode of the weathering deterioration is slow and continuous, the destructive mode cannot be seen in a short time. Therefore, although some grottos suffer widespread weathering deterioration, the degree value is not large.

The calculation result of the deterioration degree is consistent with the investigation. The values of NO.211, NO.213, NO.805 and NO.806 are between 0 and 0.2, which means that their preservation conditions are good.
In the investigation, the main deteriorations in these four groups were rock powdering weathering, surface pollution, pigment layer peeling off and microorganism pollution. Weathering deterioration is much more prevalent than stability deterioration. Combined with the quantity and weight of the deterioration, the value of these four grottos is low, which means that the preservation condition is good. Taking NO.806 as an example, the rock powdering weathering data are $17.69 \mathrm{~m}^{2}$, the surface pollution is $3.01 \mathrm{~m}^{2}$, the pigment peeling off is $5.27 \mathrm{~m}^{2}$, and the microorganism pollution is $1.70 \mathrm{~m}^{2}$, while the only four stability deteriorations are scaling off $\left(2.29 \mathrm{~m}^{2}\right)$, detachment $\left(0.09 \mathrm{~m}^{2}\right)$, body loss $\left(0.04 \mathrm{~m}^{2}\right)$, and cracks $(4 \mathrm{~m})$. Contrasting the two kinds of deteriorations, the weathering deterioration data are much larger than the stability deterioration data. Combined with the weight shown in Table *, although the deterioration data are large, the preservation is good. The value of NO.86, NO.214. NO.400, NO.513, NO.535 and NO.689 are between 0.2 and 0.4 , and the preservation condition is moderate; they account for $54.5 \%$ of the survey objects. In these six grottos, both stability deterioration and weathering deterioration developed, and the quantity of stability deterioration was greater than that in the former four grottos. Only one grotto deterioration degree was very poor, namely, NO.512. In the investigation, NO.512 is the largest grotto, and stability deterioration is the majority factor. Large cracks run through the main body of the grotto, water deterioration spreads at the base of the sculpture, and body loss and detachment can be found on every side of the grotto. The deteriorations above all will result in grotto instability. The weight and quantity of the deteriorations are both large; therefore, the deterioration degree of NO.512 is the largest, and the preservation condition is very poor, which should be a conserved priority in conservation. In general, the result follows the normal distribution.

Most grottos suffer various deteriorations simultaneously, and different deteriorations affect the preservation of the grotto to different degrees. The deterioration degree of the grotto is determined by all the deteriorations. In conservation, the first problems conservators should answer is which deterioration is the 
most common, which one has the greatest affect, and which grotto should be conserved first. Most related existing studies address the quantitative assessment of one deterioration or risk the grotto or the heritage relics may face $[11,12,16,19,20]$. Their study methods offer an important reference for this research, but the results cannot offer a direct basis for conservators. This research attempts to identify the weight of every deterioration and assess the deterioration degree of the grotto in a quantitative manner. The calculation method and results compensate for the deficiency of quantitative evaluation of grotto deterioration and offer a basis for conservation. Grottos from the Tang Dynasty in Sichuan are distributed widely, and the number is large. It is crucial to determine the conservation order when facing a large number of grottos. Taking the Guangyuan ThousandBuddha grotto as an example, there were 949 grottos and more than 7000 stone sculptures, most of which suffered deteriorations to different extents. Both the value and deterioration degree should be considered when the conservation order is determined. Grottos with high values and high degrees of deterioration should be a conserved priority, such as NO.512 in this research. Meanwhile, deterioration with high weight should be treated as a priority when conservation is conducted, which means that stability deterioration should be considered a priority. This research result and calculation method offer a possible solution for conservation and may be practised in future work.

There are some deficiencies in this research. One important aspect is regional deterioration, namely, geological disasters, which play a crucial role in preserving grotto conditions. Limited by the time and research conditions, in this study, we did not investigate geological disasters, which may lead to the disappearance or overall damage of the grotto. Thus, the deterioration degree of the grotto was reduced to a certain extent. Considering both the regional deterioration and the main body deterioration of the grotto, the grotto deterioration degree and the preservation condition can be reflected reliably and objectively.

\section{Conclusion}

The authors take 11 grottos from the middle Tang Dynasty in the Guangyuan Thousand-Buddhas grotto as survey objects. By building a hierarchical structure and constructing a judgement matrix, the weight of 15 deteriorations is calculated, and the deterioration degree of 11 grottos can be shown in a quantized way. From the results, we can conclude the following:

1. A hierarchical structure of the deterioration degree was established: the deterioration degree of the grotto was defined as the goal; stability deterioration and weathering deterioration made up the criterion layers; and the index layer included 15 deteriorations.

2. Stability deterioration influences the grotto deterioration degree more than weathering deterioration in the short term. The weight of stability deterioration is 0.75 , and weathering deterioration is 0.25 . The more stability deterioration the grotto suffers, the larger the deterioration degree is.

3. The 15 deteriorations have different weights in affecting the deterioration degree. The top four deteriorations are body loss $(\mathrm{C} 4,0.246)$, scaling off $(\mathrm{C} 1,0.146)$, cracks $(C 5,0.146)$, and water deterioration $(C 3,0.094)$. These four types are the main deteriorations that most influence the preservation condition of the grotto. Rock powdering weathering (C7), pigment layer peeling off (C10) and surface pollution (C14) are the most common deteriorations in Guangyuan Thousand-Buddhas grottos and are distributed in almost every grotto. Although they have less weight, they should be considered in a long conservation term.

4. The deterioration degree of 11 objects can be classified as good, moderate, poor and very poor. Based on the calculation result, grottos that were preserved in good condition accounted for $36.6 \%$, for a total of four grottos, and the deterioration of these grottos was mainly weathering deterioration. There were five grottos in moderate condition, accounting for 54.5\%, in which stability deterioration and weathering deterioration both developed. The grotto preserved in the "very poor" condition is the only one because this grotto is the largest one of the objects, and the quantities of the two categories of deterioration are both large. This result is in accordance with a normal distribution and offers a basis for further consolidation and conservation.

\section{Abbreviations}

AHP: Analytic hierarchy process; C. I: Consistency index; R. I: Random index; C. $\mathrm{R}$ : Consistency ratio; D: Deterioration degree.

\section{Acknowledgements}

The authors would like to thank the Guangyuan Thousand-Buddha Grotto Art Museum for their support with this research.

\section{Authors' contributions}

$X Y$ and $F Z$ designed the research project; $F Z$ was responsible for investigation and data collection. XY analysed the data and wrote this publication. Both authors read and approved the final manuscript.

\section{Funding}

This research is supported by "the Fundamental Research Funds for the Central Universities", Southwest Minzu University (Grant Number: 2020SYBPY08) and the National Key R\&D Program of China (Grant Number: 2020YFC1522903).

Availability of data and materials

The data used in this research are published in this paper, and they are all available from the corresponding author upon reasonable request. 


\section{Declarations}

\section{Competing interests}

The authors declare that they have no competing interests.

\section{Author details}

${ }^{1}$ Department of Tourism and History Cultural, Southwest Minzu University, Chengdu 610041, Sichuan, People's Republic of China. ${ }^{2}$ Cultural Relics and Archaeology Institute of Sichuan, Chengdu 610041, Sichuan, People's Republic of China.

Received: 20 July 2021 Accepted: 22 January 2022

Published online: 07 February 2022

\section{References}

1. Bai S. Chinese grotto study. Cultural relic Press.1996;1:1-3. (in Chinese)

2. Zhang BF. Survey of Grotto conservation technology. Beijing: Cultural Relics Press. 2017:1: 4. (in Chinese)

3. Lei YH. Preliminary discussion of partition and stage of Sichuan Grotto, Chengdu. Archaeol Stud. 2016;00:347-73 (in Chinese)

4. Wang JH, Chen JQ. Current status and future development of cave temples protection in China. Southeast Cult. 2018;01:06-14 (in Chinese).

5. Zhang J, Li Z, Li Li, Liu J, Liu D, Shao M. Study on weathering mechanism of sandstone statues in Southwest China: example from the sandstone of Niche of Sakyamuni Entering Nirvana at Dazu Rock Carvings. Nat Hazards. 2021:108:775-97.

6. Liu RZ, Zhang BJ, Zhang H, et al. Deterioration of Yungang grottos: diagnosis and research. J Cult Herit. 2011;12:494-9.

7. Yan H, Fu Z, Kang J. The investigation and protection about disease of area in Wu Guantun grottos. J Shanxi Datong Univ. 2018;10:45-50 (in Chinese).

8. Bo H, Zhang N, Guo H. Physical weathering mechanism and influencing factors of Guangyuan thousand-buddha grotto. Chin Cult Herit. 2018;05:34-9 (in Chinese)

9. Zhang $\mathrm{N}, \mathrm{Bo} \mathrm{H}, \mathrm{Guo} \mathrm{H}$. Chemical weathering mechanism of Guangyuan thousand-buddha grotto. Chin Cult Herit. 2018;05:40-5 (in Chinese).

10. Fiore P, Sicignano E, Donnarumma G. An AHP-based methodology for the evaluation and choice of integrated interventions on historic buildings. Sustainability. 2020;12:5795.

11. Guo Z, Chen W, Zhang J, et al. Hazard assessment of potentially dangerous bodies within a cliff based on the Fuzzy-AHP method: a case study of the Mogao Grottoes, China. Bull Eng Geol Env. 2017;76:1009-20.

12. Cui K, Yumin Du, Zhang Y, Guopeng Wu, Li Yu. An evaluation system for the development of scaling off at earthen sites in arid areas in NW China. Herit Sci. 2019;7:14.

13. Liu F, et al. An approach to assess the value of industrial heritage based on Dempster-Shafer theory. J Cult Herit. 2018;32:210-20.

14. Nicu IC. Application of analytic hierarchy process, frequency ratio, and statistical index to landslide susceptibility: an approach to endangered cultural heritage. Enviro Earth Sci. 2018;77:79.

15. Ravankhah M, Schmidt M, Will T. An indicator-based risk assessment framework for World Heritage sites in seismic zones: the case of "Bam and its Cultural Landscape" in Iran. Int J Disaster Risk Reduct. 2021;63:102405.

16. Kittipongvises S, Phetrak A, Rattanapun P, et al. AHP-GIS analysis for flood hazard assessment of the communities nearby the world heritage site on Ayutthaya Island, Thailand. Int J Disaster Risk Reduct. 2020;48:101612.

17. Eskandari S. A new approach for forest fire risk modelling using fuzzy AHP and GIS in Hyrcanian forests of Iran. Arab J Geosci. 2017;10:190.

18. Shi L, Qiu M, Teng C, Wang Y, Liu T, Xingyue Qu. Risk assessment of water inrush to coal seams from underlying aquifer by an innovative combination of the TFN-AHP and TOPSIS techniques. Arab J Geosci. 2020;13:600.

19. Ge C, Zhang LQ. The research of earthquake risk assessment method on Chinese Buddhist cave temples. Archit Cult. 2013:4:104-7 (in Chinese).

20. Liang L, Gong A, Sun $Y Z$, Chen $Y H$. Seasonal rainstorm and flood risk assessment method for immovable cultural relics: a case study of national ancient sites in Fujian province. Geomat Inf Sci Wuhan Univ. 2021;01:1-17 (in Chinese)
21. Saaty TL. The analytic hierarchy process: a 1993 overview. Cent Eur J Oper Res Econ. 1993;2:119-37 (in Chinese)

22. Luo Y, Zhang L, Zhang Y. Method for risk assessment of geological hazards. Cent Geol. 1998:8:123-5 (in Chinese)

23. He L, Wang Na, Zhao X, Zhou T, Xia Y, Liang J, Rong Bo. Polychromic structures and pigments in Guangyuan thousand-buhhda grotto of Tang dynasty (China). J Archaeol Sci. 2012;39:1809-20.

24. Sun M. A system for evaluating the deterioration of earthen sites. Sci Conserv Archeol. 2012:8:27-32 (in Chinese)

25. State Administration of Cultural Heritage of People's Republic of China. Classification and legend on the deterioration of ancient stone objects (WW/T 0002-2007). (in Chinese).

26. Saaty TL. Rank from comparisons and from rating in the analytic hierarchy/network processes. Eur J Oper Res. 2006;168:557-70.

27. Chen S, Liu W, Bai Y, Luo X, Li H, Zha X. Evaluation of watershed soil erosion hazard using combination weight and GIS: a case study from eroded soil in Southern China. Nat Hazards. 2021;109:1603-28.

\section{Publisher's Note}

Springer Nature remains neutral with regard to jurisdictional claims in published maps and institutional affiliations.

\section{Submit your manuscript to a SpringerOpen ${ }^{\circ}$ journal and benefit from:}

- Convenient online submission

- Rigorous peer review

- Open access: articles freely available online

- High visibility within the field

- Retaining the copyright to your article

Submit your next manuscript at $\boldsymbol{\nabla}$ springeropen.com 